\title{
Service Quality Failure and Recovery Imperatives: Implications for Airlines Owned by South Africa
}

\author{
Nicholas O. Mantey, Vannie Naidoo \\ University of KwaZulu-Natal, Durban, South Africa \\ manteyn@ukzn.ac.za,naidoova@ukzn.ac.za
}

\begin{abstract}
This article reports on a study that examined service quality and recovery among South African airlines. Service quality is pivotal in the airline industry as service failures could negatively affect operations. The authors created the acronym "AOSA" which stands for "airlines owned by South Africa" for the purposes of anonymity and confidentiality in order to protect the airlines' identity. A quantitative research approach was used with a cross-sectional analysis (sample survey) conducted with passengers of South African-owned airlines. The questionnaire was designed using a Likert scale tool, adapted to the SERVQUAL model. A nonprobability convenient sampling method was used to collect primary data from 684 passengers at O.R.Tambo International Airport in Johannesburg and King Shaka International Airport in Durban. The key findings were that: (1) significant statistical gaps exist between passengers' expectations and perceptions of AOSA's service quality and that unsatisfactory service quality is antecedent to service failure. (2) Unsatisfactory service quality is tantamount to service failure in the provision of services by AOSA. (3) A significant positive correlation exists between service quality and the dimensional variables of tangibility, reliability, responsiveness, assurance, and empathy of AOSA. In conclusion, AOSA service quality is unsatisfactory, and management should take steps to empower and train staff in service recovery techniques in other to avoid service failures.
\end{abstract}

Keywords: Intangibility, SERVQUAL, service failure, service quality, recovery

\section{Introduction}

Airline passengers have high expectations of quality service and valued customer-service performance prior to embarking on a journey. However, it is not uncommon for airlines to renege on promises to passengers. Passengers' expectations are sometimes not fulfilled because of service failure experiences. As the literature review in this article shows, many scholars have examined airline passengers' expectations of quality service in recent years. Such interest is a consequence of the important role of air travel, which pervades every sector of society. The airline mode of transport has transformed human movement in terms of travelling and connecting people. However, underlying air travel is the passenger's desire to receive top service quality, regardless of the price. The study investigated service quality failure and its implications for AOSA. It examined the subject from four perspectives: the imperatives of service quality failure and recovery for airlines based on the existing literature; the implications of services failure for AOSA; the implications for managers in the South African airline industry; and the extent to which this study provides insight from a managerial point of view and its contribution to knowledge.

Theoretical Models: The main theoretical models underpinning the study were the SERVQUAL and Gaps models (Parasuraman et al., 1985: 41-50; 1988: 12-40; Lovelock \& Wirtz, 2011:406). These models posit that service quality to customers is centred on five dimensional service(s) areas, tangibility, reliability, responsiveness, assurance, and empathy which the service firm should deliver at an exceptional level (Parasuraman et al., 1988; Chikwendu et al., 2012:118; Aydin \& Yildirim, 2012: 219 -230).Thirty-six serviceattribute statements were used, classified under these dimensions (Table 1). All the attribute statements were plotted on a 5-point Likert-type scale to determine the gaps. An extensive literature review was conducted and three hypotheses were posed and tested in respect of the service quality of AOSA.

H1: The gaps between passengers' expectations and perceptions of service quality are antecedent to service failure.

H2: Unsatisfactory service quality delivery to AOSA passengers is tantamount to service failure, which warrants the implementation of service recovery strategies. 
H3: There is a positive correlation between service quality and the dimensional variables, tangibility, reliability, responsiveness, assurance, and empathy.

\section{Literature Review}

Service failure and recovery is becoming a topical issue among academics, as customers are demanding value for money and excellent service from service providers across all service sectors, including airlines. The service imperatives of customers and the need to ensure quality in the market place are compelling airlines to find means to recover from the inevitable reality of service failure (Weber \& Sparks, 2010: 547-564).

Imperatives of service quality failure and recovery: Airline passengers occasionally experience undesirable service(s) encounters or transactions with airline companies. In service marketing, this can be considered as service failure - a situation in which the airline failed to render the promised service(s) to the passenger. The service encounter, referred to in the literature as "the moment of truth" (Fitzsimmons \& Fitzsimmons, 2011:214; Coye, 2004:54; Vargo \& Lusch, 2004:3) is the first contact between the passenger and the airline. The airline mode of transport involves several procedures and multiple processes (Tolpa, 2012: 62). This creates further challenges in providing quality services because the passenger evaluates each process at its respective level. The processes include cover seat reservations, ground service, flight operation, cabin facilities, meal service, cabin service, baggage delivery and appropriate responses to complaints (Tolpa, 2012: 62). According to Namukasa (2013:520), the passenger's quest for service quality commences the moments they decide to embark on a journey. Demands for quality service may include arranging to purchase the ticket, demanding pre-flight services, going through check-in and departure procedures (Namukasa, 2013:520). Onboard, passengers would continue to demand in-flight services until the end of the journey when they expect post-arrival services including luggage handling (Tolpa, 2012: 62).

Each of these activities offers an opportunity for the passenger to evaluate the airline's services. Passengers are able to compare their expectations with perceptions of the services received. Failure to provide satisfactory quality service during each of these encounters will cause passengers to deem the service encounter as a failure and trigger complaints (Chikwendu, Ejem \& Ezenwa, 2012; Tolpa, 2012: 62). Consequently, service failure in general can be considered as under performance of service(s) by the service provider or firm (Bennett, 2002:311). From an airline service delivery perspective the determinants of what constitute excellent services are complicated as the passenger judges services based on a range of service encounters/processes (Coye, 2004:54). A single bad experience could overshadow positive services received, resulting in the passenger labeling the encounter service a failure (Ro \& Mattlila, 2015:95). For example, should the airline perform well in every aspect of the travelling processes/procedures but fail to deliver the passenger's baggage at the destination, the passenger may consider the entire travelling experience as service failure on the part of the airline.

Thus, while it is acknowledged that what constitutes excellent service quality in the airline industry is hard to define and debatable, passengers' complaints should be perceived as failure of service delivery standards (Timm, 2008: 126). Moreover, complaints should be regarded as an opportunity to gain valuable feedback from passengers, which could prompt the airline to upgrade its service quality standards (Ro \& Mattlila, 2015:95; Timm, 2008: 126). In view of the intangible characteristics of services, difficulties arise in precisely defining service quality. The divergence between service expectations and perceptions of the services delivered by the airline might result in satisfaction or dissatisfaction (Coye, 2004:54; Gilbert \& Wong, 2003:519). When perceptions of the services received exceed expectations, the passenger will be satisfied (Naidoo, 2015: 43). In contrast, when the service falls short of expectations, the customer will be disappointed and the service quality can be considered as a failure. The firm will then need to make a conscious effort to recover from service failure to avoid reputational risks, and negative word-of-mouth publicity. A negative corporate reputation because of service failure may harm the firm's image. Service quality is centered on principles defined in previous studies by Parasuraman et al. (1985: 41-50; 1988: 1240); and Lovelock and Wirtz (2011:406). Using the constructs of a well-known evaluation tool such as the SERVQUAL (Parasuraman et al., 1985: 41-50; 1988: 12-40) (which was used in this study), one is able to measure gaps in service and determine if there were differences between expectations and perceptions in the service offering. 
The implication of services failure- AOSA: In light of the competitive environment in which AOSA operate, it is crucial for these companies to avoid service failure. The manner in which airlines render services may positively or negative impact future relations with their customers (Siu, Zhang \& Yau, and 2013:675). Services failure would result in dissatisfaction. For example, lost or damaged baggage, discourteous flight attendants, overbooking, and other poor services from staff may affect passengers' perceptions of the airline company. These situations demand that the airline and its personnel adopt a service-recovery strategy in order to satisfy the passenger (Grönroos, 2007:125; Nikbin, Marimuthu, Hyun, \& Ismail, 2015:240; Weber \& Sparks, 2010: 548).

Service failure and recovery: Extremely unhappy customers may express their dissatisfaction by switching airlines or spreading negative word-of-mouth (Mittal, Huppertz, \& Khare, 2008:195; Terblanche, 2015:200). However, many simply remain silent (Ro \& Mattila, 2015:95). Ro and Mattila's (2015:95) study revealed that customers who tend to be silent about service failure either allow the firm another opportunity to improve the quality of its service, or simply decide not to take any action. The complex nature of managing customers' responses has heightened scholarly interest in the causes of service failure, as well as recovery strategies (Nikbin et al., 2015:240; Weber \& Sparks, 2010:548-564). In the field of organizational research, scholars have investigated these issues using the justice and fairness theory (Weber and Sparks, 2010:548) (see Bradley \& Sparks, 2009:129; Nikbin et al., 2015:240; Namkung \& Jang, 2009:397; Ro \& Mattila, 2015:95; Sparks \& Fredline, 2007: 242; Wang, Matilla, \& Bartlett, 2009:796, to name but a few). Ideally, service firms should make a conscious effort to satisfy their customers' service expectations, especially in the first encounter. This would increase customers' confidence in the competence of the firm in subsequent encounters (Siu et al., 2013:675). Serving the customer appropriately the first time round is important for the survival of a service firm (Grönroos, 2007:125). Accordingly, Arif, Gupta, and Williams (2013: 1) are of the opinion that service firms that avoid failure perform better than those recovering from service failures. Studies identify three possible scenarios for service failure: services that are unavailable, those performed too slowly and deplorable services (Grönroos, 2007:125). All three scenarios, which represent the pessimistic aspect of service failure, could negatively affect the relationship between a service firm and its customers (Siu et al., 2013:675).

However, some scholars have noted that service failure also offers reason to be optimistic (Sengupta, Balaji, \& Krishnan, 2014:2), as front-line staff can adopt creative measures to turn service failure into success. The creativity, experience, and professionalism of front-line staff are vital in transforming potentially damaging service failure into recovery and success to satisfy the customer (Sengupta et al., 2014:2; Luk \& Layton, 2004:54; Murphy, Bilgihan, Kubiskova, \& Boseo, 2015:304). Thus, adopting successful recovery strategies might convert service failure into increased customer loyalty (Murphy et al., 2015:304). Nonetheless, some scholars maintain that service failure is preventable if certain recovery strategies and procedures are implemented (Chang \& Chang, 2010:340; Chou, 2015: 119; Hu, Lu, Tu, \& Jen, 2013: 2255). In the airline industry in which the AOSA operate, recovery from service failure is crucial. The reputational image of an airline will be compromised if it is unable to deliver valued and excellent services to passengers. Service failure and a lack of recovery strategies might cause passengers to switch to rival airlines (Namukasa, 2013:530; Luk \& Layton, 2004:54). Passengers' complaints should therefore be regarded as the failure of service-delivery standards, or service failure (Ro \& Mattila, 2015:95); and should be viewed as appropriate feedback and an opportunity to respond to complaints (Timm, 2008:126).

Avoiding Service failure: The literature identifies measures that service firms, including airlines could adopt to avoid service failure for the benefit of all concerned - the firm, frontline staff, and customers (air passengers in this case). This section reviews the parties' responsibilities under the service-encounter triad. The service failure recovery strategy should commence at the beginning of the transaction and last until its completion. Service failure recovery strategies should cover three main areas: deal with services that are unavailable, address slow performance, and deal with unacceptable service (Grönroos, 2007:125; Mantey, 2015: 57). Strategies to minimize service failure and recover from such occurrences include improving the firm's organizational culture; staff empowerment, control systems, selection and training of frontline staff; and customer involvement in the service encounter (Andersson-Cederholm \& Gyimothy, 2010:266; Craig, 2014: 299; Levine, 2015: 840; Ro \& Mattila (2015:95). These are discussed in more detail below. 
Organizational culture: A service failure recovery strategy is centered on the organizational culture and values where a conscious effort is made to deliver excellent service to customers at all times. Responsibility for this endervour starts with management (Andersson-Cederholm \& Gyimothy, 2010:266).The literature notes that the organizational or corporate culture is established by the founders or top management based on certain cultural values (Blythe \& Zimmerman, 2005:160) that dictate how things are done in the organization (Levine, 2015: 840; Craig, 2014:299). Frontline staff's responsibility to deliver service quality to customers should flow from management (Blythe \& Zimmerman, 2005:160) which should initiate service quality strategies. Service personnel are therefore empowered by management to make sound decisions on behalf of the organization (Craig, 2014: 299).

Empowerment: Empowerment aims to equip frontline staff to perform the responsibilities entrusted to them by the organization and is different from delegating authority. From a service quality perspective, empowerment entails entrusting frontline staff with the responsibility of making certain decisions that enhance the efficiency of the organization and enable it to deliver top class services to customers. On the other hand, delegation means acting on behalf of another person to perform a particular task. The person who delegated the task is not exonerated from his/her responsibility should something go wrong (Webb, 2002: 35; Craig, 2014:299). Frontline staff is not delegated to perform a task, but rather empowered by the service firm to make responsible decisions and service the customer in line with the organization's philosophy (Webb, 2002: 35). The extent of empowerment of frontline staff will determine their professional ability to successfully recover from possible service failure (Mantey, 2015:57; Ro \& Mattila, 2015:95).

Control systems: Control systems are mechanisms employed by firms to further empower and build the confidence of frontline staff, based on shared values and the organizational culture. Control systems serve as a boundary or set the confines within which frontline staff can take responsibility in offering services to the customer. They can also be deployed as a mechanism to appraise measurable goals and analyze performance targets (Fitzsimmons \& Fitzsimmons, 2011:217; Webb, 2002: 38). Service firms use control systems to measure both the performance of frontline staff and feedback from customers.

Frontline staff: Frontline staff is the first point of contact between the customer and the service provider. As representatives of the firm, frontline staff is usually authorized to conduct business with the customer. The relationship between the service provider and the customer generally commences at this stage (Janawade, Bertrand, Léo \& Philippe, 2015:278). Customers evaluate a firm's service during the service encounter process and form opinions; consequently front office personnel should not only have appropriate knowledge of the service on offer, but should be competent in managing customer relations (Janawade et al., 2015:278). Moreover, they are expected to perform their tasks efficiently based on standard procedures, and apply creative judgment, bearing in mind customer satisfaction (Terblanche, 2015:203). Frontline staff should thus have the following qualities: versatility, patience when customers are vague about their needs, the ability to analyze behavioral changes in customers, and empathy. Janawade et al. (2015:278) emphasized that the selection process for frontline staff is of paramount importance. Service firms should ensure that personnel are only employed after rigorous background checks and psychometric testing.

Selection and Training of Frontline staff: It is imperative to train frontline staff to identify possible service failures and techniques to recover from such situations. Wilson, Zeithaml, Bitner, and Gremler (2008: 208) note that, "To build a customer-oriented, service-minded workforce, companies must (1) hire the right people, (2) develop people to deliver service quality, (3) provide the needed support systems, and (4) retain the best people". These could be achieved by using the best human resources practices measure to select customer-oriented staff to comply with the firm's organizational culture and ethos to deliver quality service (Fitzsimmons \& Fitzsimmons, 2011:218; Wilson et al., 2008: 208). Furthermore, "A complex combination of strategies is needed to ensure that service employees are willing and able to deliver quality services and that they stay motivated to perform in customer-oriented, service-minded ways" (Wilson et al. 2008: 208). Staff in all sections of the firm should be trained and empowered so as to satisfy customers' service delivery expectations and to ensure recovery in the event of service failure (Karatepe \& Vatankhah, 2014: 115; Yavas, Karatepe, \& Babakus, 2011:304). All airline employees should undergo regular training in order to avoid or reduce service failure (Nikbin, Hyun, Iranmanesh, Maghsoudi \& Jeong (2015:14b). Moreover, the demands of globalization, exacerbated by liberalization and deregulation in the airline industry, have exerted severe 
pressure on airlines to provide superior service, while retaining personnel (Amankwah-Amoah, 2015:2). Therefore firms should ensure effective human resources management and adopt human capital strategies to recruit, train, and retain staff (Amankwah-Amoah, 2015:2; Gardner, Stansbury, \& Hart, 2010: 341).

The Customer and service-encounter: The relationship between the customer and the passenger is critical in the service-encounter triad. Frontline staff should therefore handle customers with the utmost care. Perceptions are formed from the start of each transaction and the customer gauges whether or not expectations are met during each stage of the encounter. Thus, it is critically important for service firms to train their frontline staff in communication so that they are able to address possible service failure and take steps to recover from such situations. Frontline staff should also be trained to deal with difficult and unreasonable customers who have the potential to cause service failure, and to recover quickly (Fitzsimmons \& Fitzsimmons, 2011:221. However, despite all efforts, sporadic service failures may occur. In such situations, frontline staff must be able to recover as quickly as possible so as to satisfy passengers' expectations (Mantey, 2015: 58).

\section{Methodology}

The study sourced rich and extensive data from the literature, which was the core of the secondary data for this research. The secondary data were obtained primarily from textbooks, journal articles, statements from scholars in the subject area, and the opinions of academics and experts from the airline and allied industries. A Likert-scale type instrument adapted from the SERVQUAL model (Parasuraman, Zeithaml, \& Berry, 1985:41-50) was used to collect the primary data using the direct survey approach. The primary data was collected from 684 passengers at O.R.Tambo International Airport in Johannesburg and King Shaka International Airport in Durban. Non-probability convenient sampling was employed. The Cronbach alpha scores for the study were 0.810, indicating good reliability. A pilot study was used to test the validity of the questionnaire. The ideal level of reliability is achieved if Cronbach alpha scores are over 0.70 (Raut \& Veer, 2014:68; Sekaran \& Bougie, 2013:228).

\section{Results}

The first hypothesis centred on the gaps between expectations and perceptions in delivering service quality to AOSA passengers (Table 1). The service quality gap was analysed by comparing the mean scores between perceptions and expectations (Table 1).

Mean scores of perceptions and expectations: Based on the SERVQUAL and Gaps models (Parasuraman et al., 1985: 41-50; 1988: 12-40; Lovelock \& Wirtz, 2011:406, the first hypothesis tested was:

H1: The gaps between passengers' expectations and perceptions of service quality are antecedent to service failure.

\section{Table 1: Summary of AOSA Quality Gaps scores- Expectations and Perceptions}

\begin{tabular}{lllll}
\hline & Attributes & $\begin{array}{l}\text { Expectations } \\
\text { Mean(M) }\end{array}$ & $\begin{array}{l}\text { Perceptions } \\
\text { Mean(M) }\end{array}$ & $\begin{array}{l}\text { SQ=P-E) } \\
\text { M(P-E) }\end{array}$ \\
\hline Tangibility & AS1 & 4.525 & 3.594 & -0.931 \\
& AS2 & 4.497 & 3.506 & -0.991 \\
& AS3 & 4.615 & 3.538 & -1.077 \\
& AS4 & 4.67 & 3.617 & -1.053 \\
AS5 & 4.572 & 3.396 & -1.176 \\
& AS6 & 4.667 & 3.48 & -1.187 \\
& AS7 & 4.662 & 3.174 & -1.488 \\
& AS8 & 4.575 & 3.341 & -1.234 \\
& AS9 & 4.525 & 3.034 & -1.491 \\
\hline
\end{tabular}




\begin{tabular}{|c|c|c|c|c|}
\hline & Attributes & $\begin{array}{l}\text { Expectations } \\
\text { Mean(M) }\end{array}$ & $\begin{array}{l}\text { Perceptions } \\
\text { Mean(M) }\end{array}$ & $\begin{array}{l}S Q=P-E) \\
M(P-E)\end{array}$ \\
\hline \multirow{11}{*}{ Reliability } & AS10 & 4.564 & 3.127 & -1.437 \\
\hline & AS11 & 4.392 & 3.069 & -1.323 \\
\hline & AS12 & 4.626 & 3.263 & -1.363 \\
\hline & AS13 & 4.703 & 3.314 & -1.389 \\
\hline & & 59.593 & 43.453 & -16.14 \\
\hline & AS14 & 4.636 & 3.184 & -1.452 \\
\hline & AS15 & 4.621 & 3.216 & -1.405 \\
\hline & AS16 & 4.615 & 3.32 & -1.295 \\
\hline & AS17 & 4.671 & 3.711 & -0.96 \\
\hline & AS18 & 4.675 & 3.357 & -1.318 \\
\hline & AS19 & 4.663 & 3.184 & -1.479 \\
\hline \multirow{9}{*}{ Responsiveness } & AS20 & 4.668 & 3.073 & -1.595 \\
\hline & AS21 & 4.668 & 3.148 & -1.52 \\
\hline & AS22 & 4.596 & 2.871 & -1.725 \\
\hline & & 41.813 & 29.064 & -12.749 \\
\hline & AS23 & 4.652 & 3.095 & -1.557 \\
\hline & AS24 & 4.674 & 3.148 & -1.526 \\
\hline & AS25 & 4.675 & 3.161 & -1.514 \\
\hline & AS26 & 4.702 & 3.094 & -1.608 \\
\hline & AS27 & 4.677 & 2.987 & -1.69 \\
\hline \multirow{5}{*}{ Assurance } & AS28 & 4.661 & 3.015 & -1.646 \\
\hline & & 28.041 & 18.5 & -9.541 \\
\hline & AS29 & 4.665 & 3.111 & -1.554 \\
\hline & AS30 & 4.683 & 3.044 & -1.639 \\
\hline & AS31 & 4.604 & 3.007 & -1.597 \\
\hline \multirow{7}{*}{ Empathy } & AS32 & 4.64 & 2.868 & -1.772 \\
\hline & AS33 & 4.683 & 2.991 & -1.692 \\
\hline & & 23.275 & 15.021 & -8.254 \\
\hline & AS34 & 4.678 & 3.006 & -1.672 \\
\hline & AS35 & 4.702 & 2.993 & -1.709 \\
\hline & AS36 & 4.646 & 2.658 & -1.988 \\
\hline & & 14.026 & 8.657 & -5.369 \\
\hline
\end{tabular}

Source: Mantey \& Naidoo (2016)

A close examination of the expectations mean scores for all the respective attributes and the service quality dimensions, namely, tangibility, reliability, responsiveness, assurance, and empathy indicated that the mean scores were $(\mathrm{M}=>4)$. Conversely, the perceptions mean scores for all the respective attributes and the service quality dimensions mean scores were $(M=>3)$. Thus, there were significant gaps between passengers' perceptions of AOSA's services and their expectations. Previous studies on the airline industry that used the SERVQUAL and Gaps models produced similar results (Chikwendu et al., 2012:117-125; Aydin \& Yildirim, 2012:219-20; Shanka, 2012:173-180). Studies conducted in different parts of the world detected similar levels of expectations and perceptions of service quality (Mantey, 2015:230). These studies confirmed that air passengers expect high service quality and any provision that falls short of service excellent will be regarded 
as service failure. Hypothesis $H 1$ is in line with statistical evidence in this study and previous studies, and is therefore accepted. Numerous studies have found that passengers have extremely high expectations of service quality in the airline industry (Shanka, 2012:173; Wang et al., 2011:419; Wattanacharoensil \& Yoopetch, 2012:286) and that low- standard services that do not fit with what was promised may be regarded as service failure (Luk \& Layton, 2002: 109-128). Therefore, airline companies should endeavor to avoid service failure in rendering services to their passengers (Wattanacharoensil \& Yoopetch, 2012:280-320; Nikbin et al., 2015:14b).

Service quality gaps and service failure: Using the dataset in Table 1 the second hypothesis was tested: H2: Unsatisfactory service quality delivery to AOSA passengers is tantamount to service failure, which warrants the implementation of service recovery strategies.

Table 2: Pearson's Correlation test on the dimensional variables

\begin{tabular}{|c|c|c|c|c|c|c|}
\hline \multicolumn{2}{|c|}{ Correlations } & \\
\hline & & & & Respons & & \\
\hline & & Tangibilit & Reliability & & Assuran & e Empathy \\
\hline & & y Score 1 & Score 1 & Score 1 & Score 1 & Score 1 \\
\hline $\begin{array}{l}\text { Tangibility } \\
\text { Score } 1\end{array}$ & $\begin{array}{l}\text { Pearson } \\
\text { Correlation }\end{array}$ & 1 & $.788^{* *}$ & $.743^{* *}$ & $.734^{* *}$ & $.653^{* *}$ \\
\hline & Sig. (2-tailed) & & .000 & .000 & .000 & .000 \\
\hline & $\mathrm{N}$ & 684 & 684 & 684 & 684 & 684 \\
\hline $\begin{array}{l}\text { Reliability } \\
\text { Score } 1\end{array}$ & $\begin{array}{l}\text { Pearson } \\
\text { Correlation }\end{array}$ & $.788^{* *}$ & 1 & $.812^{* *}$ & $.760^{* *}$ & $.707^{* *}$ \\
\hline & Sig. (2-tailed) & .000 & & .000 & .000 & .000 \\
\hline & $\mathrm{N}$ & 684 & 684 & 684 & 684 & 684 \\
\hline $\begin{array}{l}\text { Responsive } \\
\text { ness Score } 1\end{array}$ & $\begin{array}{l}\text { Pearson } \\
\text { Correlation }\end{array}$ & $.743^{* *}$ & $.812^{* *}$ & 1 & $.853^{* *}$ & $.751^{* *}$ \\
\hline & Sig. (2-tailed) & .000 & .000 & & .000 & .000 \\
\hline & $\mathrm{N}$ & 684 & 684 & 684 & 684 & 684 \\
\hline $\begin{array}{l}\text { Assurance } \\
\text { Score } 1\end{array}$ & $\begin{array}{l}\text { Pearson } \\
\text { Correlation }\end{array}$ & $.734^{* *}$ & $.760^{* *}$ & $.853^{* *}$ & 1 & $.805^{* *}$ \\
\hline & Sig. (2-tailed) & .000 & .000 & .000 & & .000 \\
\hline & $\mathrm{N}$ & 684 & 684 & 684 & 684 & 684 \\
\hline $\begin{array}{l}\text { Empathy } \\
\text { Score } 1\end{array}$ & $\begin{array}{l}\text { Pearson } \\
\text { Correlation }\end{array}$ & $.653^{* *}$ & $.707^{* *}$ & $.751^{* *}$ & $.805^{* *}$ & 1 \\
\hline & Sig. (2-tailed) & .000 & .000 & .000 & .000 & \\
\hline & $\mathrm{N}$ & 684 & 684 & 684 & 684 & 684 \\
\hline
\end{tabular}

Source: Mantey \& Naidoo 2016

Table 1 shows that gaps exist in quality service delivery to AOSA passengers in relation to the degree of service quality failure for the dimensions tangibility, reliability, responsiveness, assurance, and empathy. Using the SERVQUAL and Gaps models (Parasuraman et al., 1985:41-50; 1988:12-40; Lovelock \& Wirtz, 2011:406; Naidoo \& Mutinta, 2014:219-229) the five dimensional variables were evaluated, categorised under 36 attributes for expectations and another 36 for perceptions (Table 1). The computation in Table 1 was done using the formula: Service quality $(\mathrm{SQ})=$ Perceptions (P)-Expectations (E) (Fitzsimmons \& Fitzsimmons, 2011: 116; Lovelock \& Wirtz, 2011:406; Naidoo, 2015: 43).The results (Table 1) show that significant variance emerged among all 36 attribute statements used in this study. For the sake of brevity, the analysis summarizes the dimensions focusing on the totals of tangibility, reliability, responsiveness, assurance, and empathy. It was found that the average gap score for tangibility, reliability, responsiveness, assurance, and empathy was $(M=-16(S D=11.63) ; \quad(M=-12.74(S D=7.94) ; \quad(M=-9.54(S D=6.03) ; \quad(M=-8.23$ $(S D=5.08)$ and $(M=-5.38(S D=3.44)$, respectively. In service quality gap evaluations where the perceptions values are higher than expectations, the quality of service rendered to the customer is unacceptable and tantamount to service failure on the part of the airlines. In other words, service provision by AOSA to passengers was below acceptable level, and passengers were displeased or unfulfilled. The data analysis also 
shows that service failure is reflected in all 36 attributes for the service quality dimensions tangibility, reliability, responsiveness, assurance, and empathy. Previous studies have revealed similar gaps in airlines' service quality (Namukasa, 2013:529; Arif et al., 2013:2; Baker, 2013:68; Erdil \& Ylldı, 2011:1232; Chen, 2008: 709; Wu \& Cheng, 2013:13; Aydin \& Yildirim, 2012:220; Chikwendu et al., 2012:119). The data analysis for the current study revealed gaps in AOSA's service quality in all the service dimensional areas. Therefore, AOSA should revisit their service offerings and improve the quality of their services. Based on the empirical evidence from Table 1 , and the literature, hypnosis $H 2$ is accepted.

Inferential statistics-Correlation on dimensional variables: Further tests were conducted using inferential statistics to determine the correlation between service quality and the dimensional variables tangibility, reliability, responsiveness, assurance, and empathy (Tables $2 \& 3$ ). The hypothesis tested was:

H3: There is a positive correlation between service quality and the dimensional variables tangibility, reliability, responsiveness, assurance, and empathy

Table 3: Further Pearson's Correlation test on the dimensional variables

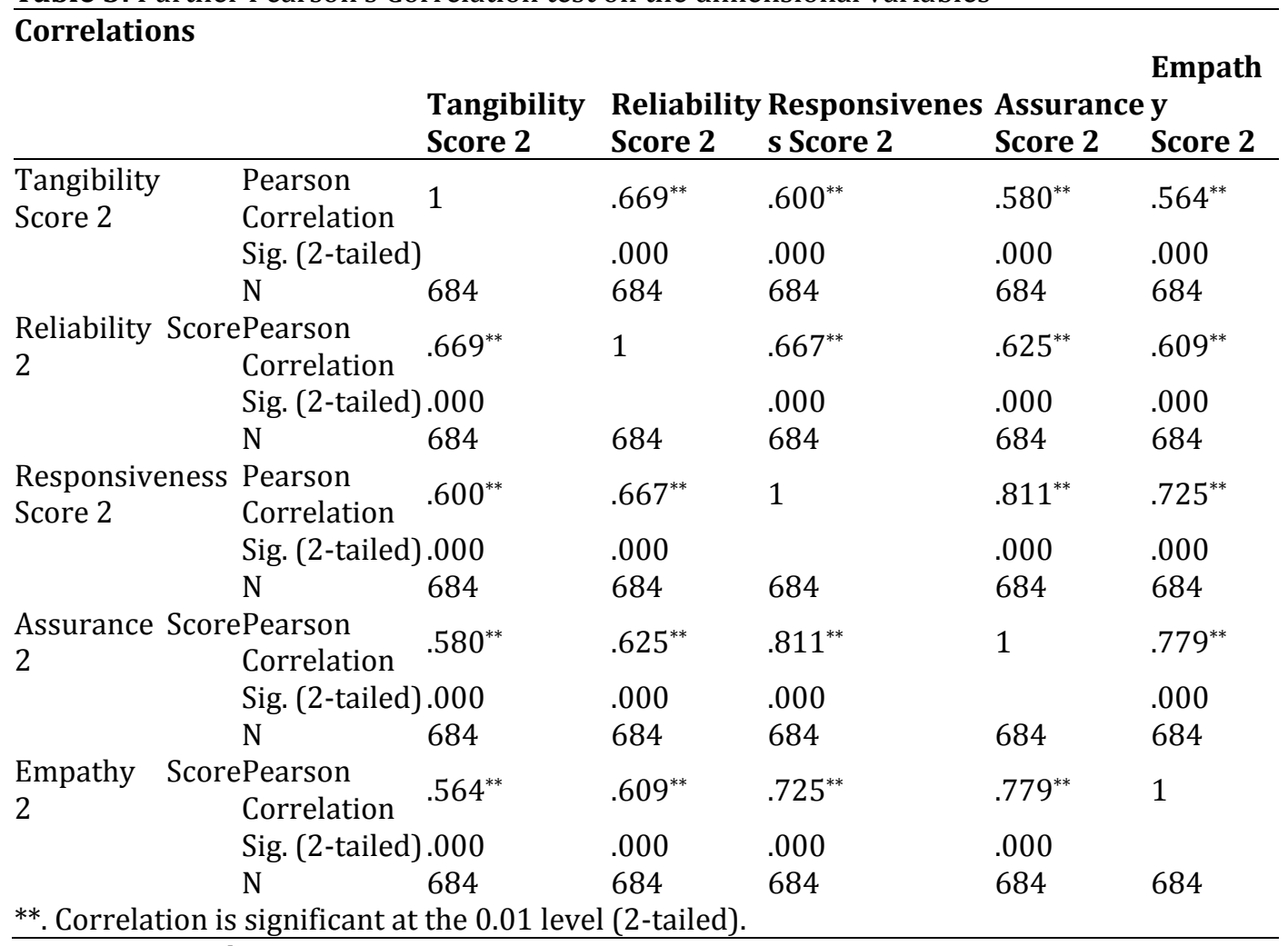

Source: Researchers

The results of the Pearson's correlation test showed that all the sub-sections were significantly correlated $(p<0.01)$. Thus, as per this test, there was significant correlation in the service quality gaps and the dimensional variables tangibility, reliability, responsiveness, assurance, and empathy, since the gaps in the dimensional variables were $(\mathrm{P}=0.000)$, indicating significant values for all the valuables. The correlation $(\mathrm{p}<0.01)$ in the variables further confirms service failure or gaps in the delivery of services to AOSA passengers. Studies conducted by Namukasa (2013:520-532) and Okeudo and Chikwendu (2013:19-28) confirm the existence of this correlation. Therefore based on the empirical evidence as per Tables 2 and 3 , and supported by the literature, hypothesis $H 3$ is accepted.

Managerial implications for AOSA: The managerial implication of the study's findings is that there is a need for airlines to review deficiencies in service quality and improve their services. South African owned airlines need to adapt to change to ward off their competitors. They must move ahead, proactively adopting service quality strategies to meet passengers' expectations and demands. While AOSA make a significant contribution 
to the country's economy, some may confront challenges in providing excellent services to their passengers. Nevertheless, excellent service quality should be embraced as a strategic tool for competitive advantage. The challenges should be confronted and heed should be taken of passengers' views in order to provide exceptional, valued-services at all times (Mantey, 2015: 1-433).The study's recommendations could be used as a guide to design measures to avoid service failure.

Contribution to Knowledge: This study contributes to knowledge by providing cognitive information to major stakeholders (academics, practitioners, and management) in the global airline industry and in particular to the South Africa airline market. It offers empirical insight into service quality failure and recovery in the South African airline industry. The study thus helps to fill the gap in empirical research in this field. The recommendations set out below could assist airline companies to avoid or reduce service failure and implement recovery measures. While service failure and recovery might be considered inconsequential by some people in the airline industry, these issues could severely affect airlines' brand image and reputation, profitability, and passenger loyalty, and patronage. The study found that the South Africa airline industry confronts challenges in terms of service quality, and service failure and recovery. It offers an overview of the status of the service offering to the air passenger in South Africa. Few studies have been conducted on these issues in South Africa and future researchers could build on its findings.

\section{Conclusion and Recommendations}

The service quality gaps in all the dimensional service quality variables, tangibility, reliability, responsive, assurance and empathy, indicate problems with the service offerings of AOSA. It is thus recommended that services should be improved at all dimensional levels. In order to minimize or eliminate future service failure and promote rapid service recovery, it is recommended that airlines should proactively anticipate potential areas of service failure. This would enable their staff to speedily respond to such challenges. Staff training in service quality failure and recovery is recommended as well as interventions to improve service delivery. Staff training and empowerment is essential in addressing passengers' complaints, making it possible for the airline to meet or exceed expectations. However, inadequate staff reward packages may cancel out the benefits of staff training and empowerment (Yavas et al., 2011:304). Furthermore, airlines should encourage passengers to voice their complaints when they are dissatisfied with the services rendered. The airline's social media platforms could be used to make it easier for passengers to provide feedback. This would require AOSA to re-engineer their systems for social media configuration. Modern Information Communication and Technology (ICT) tools, integrated with social media via the Internet could improve service provision to airline passengers (Mantey, 2015: 1-433). Furthermore, it is recommended that airlines debrief staff after a service recovery experience. Staff should be encouraged to discuss the lessons learnt during the service failure encounter with passengers and to make suggestions that could avert service failure in the future.

Other corrective programs or interventions, which airlines might consider to improve service quality, include International Standard Organizations (ISO) techniques, Total Quality Management (TQM) principles, the Six Sigma, and benchmarking tools. The study on which this article is based examined, services quality failure and recovery imperatives and implications among AOSA. It is concluded that poor service quality can lead to unhappy passengers. The study's key finding was that significant gaps exist in the services rendered by AOSA to passengers. The study's contribution to academic research is that it has brought to the fore deficiencies in service delivery among AOSA and recommended strategies to recover from service quality failures. While service quality may not be eliminated, adoption of these recommendations could drastically reduce service quality failures in the future.

Limitations and Future research: The first limitation of the study was that the instrument used for the data collection was generic and was not specifically tailored for airline companies. Airline services are unique and focus more on intangible than tangible services. An airline-centred instrument would have provided broader analysis. However, given the lack of such an instrument, the SERVQUAL was customized for the study, as recommended by its original designers (Parasuraman et al., 1985:41-50). The second limitation was that the study used non-probability sampling and its results can thus not be generalized. Thirdly, the study was restricted to South African owned airlines and did not include perceptions of foreign airlines operating in the country. Once again, this means that the study's findings cannot be generalized. Further research should be 
conducted on the approaches adapted to service failure and recovery among all airlines that fly to and from South Africa. The service quality offered by South African and foreign owned airlines should be explored. The extent to which airline management in South Africa factors service failure and service recovery into their strategic planning would also be worth investigating.

Acknowledgment: The authors acknowledge support from the School of Management, IT and Governance, University of KwaZulu-Natal in conducting this research.

\section{References}

Andersson-Cederholm, E. \& Gyimonthy, S. (2010). The service triad: modeling dialectic tensions in service encounters. The Service Industries Journal, 30(2), 265-280

Amankwah-Amoah, J. (2015). Governments, airlines and employees: an evolving relationship from 1940 to 2010. Management and Organizational History, 10(1), 1-20.

Arif, M., Gupta, A. \& Williams, A. (2013). Customer service in the aviation industry: An exploratory analysis of UAE airport. Journal of Air Transport Management, 32, 1-7.

Aydin, K. \& Yildirim, S. (2012). The measurement of service quality with SERVQUAL For different domestic airline firms in turkey. Serbian Journal of Management, 7(2), $219-230$

Baker, D. M. C. (2013). Service quality and customer satisfaction in the airline industry: A comparison between legacy airlines and low-cost airlines American. Journal of Tourism Research, 2(1), 67-77.

Bennett, J. A. (2002). Managing Tourism services: a South African perspective $.2^{\text {nd }}$ ed. Pretoria, Van Schaik.

Blythe, J. \& Zimmerman, A. (2005). Business to Business Marketing Management: A Global perspective Thomson, London.

Bradley, G. L. \& Sparks, B. A. (2009). Dealing with service failures: The use of explanations. Journal of Travel and Tourism Marketing, 26(2), 129-143.

Chang, Y. W. \& Chang, Y. H. (2010). Does service recovery affect satisfaction and customer loyalty? An empirical study of airline services. Journal of Air Transport Management, 16, 340-342.

Chen, C. F. (2008). Investigating structural relationships between service quality, perceived value, satisfaction, and behavioral intentions for air passengers: evidence from Taiwan. Transportation Research Part A, 42, 709-717.

Chikwendu, D. U., Ejem, E. \& Ezenwa, A. (2012). Evaluation of service quality of Nigerian airline using SERVQUAL model, Journal of Hospitability Management and Tourism, 3(6), 117-126.

Chou, P. F. (2015). An analysis of the relationship between service failure, service Recovery and loyalty for Low Cost Carrier travelers. Journal of Air Transport Management, 47, 119-125

Coye, R. W. (2004). Managing customer expectations in the service encounter .International Journal of Service Industry Management, 5(4), 54-71.

Craig, D. (2014). Would you like service with that? Journal of Higher Education Policy and Management 36(3), 293-304.

Erdil, S. \& Yildiz, O. (2011). Measuring service quality and comparative analysis in the passenger carriage of airline industry. Procedia- Social and Behavioral Science, 24, 1232-1242.

Fitzsimmons, J. A. \& Fitzsimmons, M. J. (2011). Service Management: Operations, strategy, Information Technology, $7^{\text {th }}$ ed, NY, McGraw Hill

Gardner, T. M., Stansbury, J. \& Hart, D. (2010). The Ethics of Lateral Hiring. Business Ethics Quarterly, 20(3), 341-369.

Gilbert, D. \& Wong, R. K. C. (2003). Passenger expectations and airlines: a case of Hong Kong based study. Tourism Management, 24, 519-532.

Grönroos, C. (2007). Services Management and Marketing: Customer Management In service Competition. $3^{\text {rd }}$ edition, John Wiley and Sons, Ltd.

Hu, K. C., Lu, M. Y., Tu, C. Y. \& Jen, W. (2013). Applying critical incidents technique to explore the categories of service failure and service recovery for Taiwanese international airlines. Journal of the Eastern Asia Society for Transportation Studies, 10, 2255-2273.

Janawade, V., Bertrand, D, Léo, P. Y. \& Philippe, J. (2015). Assessing 'meta-services': customer has perceived value and behavior, The Service Industries Journal, 35(5), 275-295. 
Karatepe, O. M. \& Vatankhah, S. (2014). The Effects of High-Performance Work Practices on Perceived Organizational Support and Turnover Intentions: Evidence from the Airline Industry. Journal of Human Resources in Hospitality \& Tourism, 13(2), 103-119.

Levine, D. (2015). Earning its Wings: a political economy analysis of China's journey toward development of the C-919 commercial airliner. Journal of Contemporary China, 24(95), 823-845.

Lovelock, C. \& Wirtz, J. (2011). Services Marketing people, Technology, Strategy. $7^{\text {th }}$ Ed, NJ, Pearson. A further gap (Gap 5) was added by Christopher Lovelock (1994:pp.112), Product Plus. New York: McGraw Hill.

Luk, S. H. T. K. \& Layton, R. (2002). Perception Gaps in customer expectations: Managers versus service providers and customers. The service Industries Journal, 22(2), 109-128.

Luk, S. T. K. \& Layton, R. (2004). Service Skills and Service Quality. Journal of Human, Resources in Hospitality and Tourism, 3(2) 33-60.

Mantey, N. O. (2015). Passengers' perceptions and expectations towards service quality of airlines owed by South Africa. PhD unpublished thesis. University of KwaZulu-Natal, Durban

Mittal, V., Huppertz, J. W. \& Khare, A. (2008). Customer complaining: The role of tie strength and information control. Journal of Retailing, 84(2), 195-204.

Murphy, K., Bilgihan, A., Kubiskova, M. \& Boseo, M. (2015). There is No 'I' in Recovery: Managements' Perspective of Service Recovery. Journal of Quality Assurance in Hospitality \& Tourism, 16(3), 303322.

Naidoo, V. (2015). A comparative study between staff and student perceptions on service quality. Journal of Contemporary Management, 12, 40-60.

Naidoo, V. \& Mutinta G. (2014). An investigation into service quality delivery at the University of KwaZuluNatal. Journal of Social Sciences, 38(3), 219-229.

Namkung, Y. \& Jang, S. (2009). The effects of interactional fairness on satisfaction and behavioral intentions: Mature versus non-mature customers. International Journal of Hospitality Management, 28(3), 397405.

Namukasa, J. (2013).The influence of airline service quality on passenger satisfaction and loyalty-The case of Uganda airline industry. The TQM Journal, 25(5), 520-532.

Naumann, P. W. E. (2011). Customer satisfaction and business performance: a firm-level analysis. Journal of Service Marketing, 25(1), 20-32

Nikbin, D., Marimuthu, M., Hyun, S. S. \& Ismail, I. (2015). Relationships of Perceived Justice to Service Recovery, Service Failure Attributions, Recovery Satisfaction, and Loyalty in the Context of Airline Travelers. Asia Pacific Journal of Tourism Research, 20(3), 239-262.

Nikbin, D., Hyun, S. S., Iranmanesh, M., Maghsoudi, A. \& Jeong, C. (2015b). Airline Travelers' Causal Attribution of Service Failure and Its Impact on Trust and Loyalty Formation: The Moderating Role of Corporate Social Responsibility. Asia Pacific Journal of Tourism Research, 21(4), 235-374

Okeudo, G. \& Chikwendu, D. U. (2013). Effect of airline service quality image and passengers' loyalty: Findings from Arik Air Nigeria Passengers. Journal of Hospitality and Management Tourism, 4(2), 19-28.

Parasuraman, A., Zeithaml, V. A. \& Berry, L. L. (1985). A conceptual model of service quality and its implications for future research. Journal of Marketing, 49(4), 41-50.

Parasuraman, A., Zeithaml, V. \& Berry, L. L. (1988). SERVQUAL: a multiple-item scale for measuring consumer perceptions of service quality. Journal of Retailing, 64, 12-40.

Raut, U. R. \& Veer, N. B. (2014). Management Research: To understand the role of epistemology in management research. Journal of Management and Science, 4, 64-70

Ro, H. \& Mattila, A. S. (2015). Silent Voices: Non-behavioral Reactions to Service Failures. Services Marketing Quarterly, 36(2), 95-111.

Sekaran, U. \& Bougie, R. (2013). Research Methods for Business -Skill- Building Approach.6 $6^{\text {th }}$ Ed John Wiley. U.K.

Sengupta, A.S, Balaji, M.S. \& Krishnan B.C. (2014). How customers cope with service failure? A study of brand reputation and customer satisfaction, "Journal of Business Research, 68 (3) 665-674.

Shanka, M.S. (2012). Measuring Service Quality in Ethiopian Airlines. Journal of Educational and Social Research, 2 (9), 173-180

Siu, N. Y. M., Zhang, T. J. F. \& Yau, C. Y. J. (2013). The roles of justice and customer satisfaction in customer retention: A lesson from service recovery. Journal of Business Ethics, 114, 675-686 
Sparks, B. A. \& Fredline, L. (2007). Providing an explanation for service failure: Context, content, and customer responses. Journal of Hospitality and Tourism Research, 31, 241-260.

Terblanche, N. S. (2015). Customers' Perceived Benefits of a Frequent Flyer Program. Journal of Travel \& Tourism Marketing, 32(3), 199-210.

Timm, P. R. (2008). Customer service: career through customer loyalty. Pearson Education Ltd, New Jersey. U.S.A.

Tolpa, E. (2012). Measuring Customer Expectations of Service Quality: case Airline Industry. Aalto University School of Economics Department of Information and Service Economy (Master's thesis)

Vargo, S. L. \& Lusch, R. F. (2004). Evolving to new dominant logic for marketing. Journal of Marketing, 68(1), 1-17.

Wang, C. Y., Mattila, A. S. \& Bartlett, A. (2009). An examination of explanation typology on perceived informational fairness in the context of air travel. Journal of Travel and Tourism Marketing, 26(8), 795-805.

Wattanacharoensil, W. \& Yoopetch, C. (2012). Thailand's human resource competencies in airline service quality: Voices from the airline industry. Journal of Human Resources in Hospitality and Tourism, $11(4), 280-320$.

Webb, R. (2002). Delegation: Burden or empowerment? Education 3-13 3-13: International Journal of Primary, Elementary and Early Years Education, 30(3), 35-41

Weber, K. \& Sparks, B. (2010). Service failure and recovery in a strategic airline alliance context: Interplay of locus of service failure and social identity. Journal of Travel \& Tourism Marketing, 27(6) 547-564.

Wilson, A., Zeithaml, V. A., Bitner M. J. \& Gremler, D. D. (2008). Services marketing: integrating customer focus across the firm. $1^{\text {st }}$ Ed. McGraw-Hill. UK

Wu, H. C. \& Cheng, C. C. (2013). A hierarchical model of service quality in the airline industry. Journal of Hospitality and Tourism Management, 20, 13 -22.

Yavas, U., Karatepe, O. M. \& Babakus, E. (2011). Efficacy of job and personal resources across psychological and behavioral outcomes in the hotel industry. Journal of Human Resources in Hospitality and Tourism, 10(3), 304-314. 